\title{
At the Crossroads of Science and Religion: A Sociological Approach
}

\section{Dr Maria Rogińska}

Institute of Philosophy and Sociology

Doi: 10.2478/ajis-2018-0024

\author{
Pedagogical University of Cracow, Poland
}

\begin{abstract}
The relationship between science and religion has recently become the topic of intense discussions in the public sphere. However, up to now empirical social sciences have neglected qualitative reconstructions of scientists' worldviews in this area. The material for my analysis is 50 in-depth interviews with biologists and physicists, employees of scientific research institutes of Polish Academy of Sciences and universities in Poland. The largest group of the respondents agreed with the idea that the areas of science and religion do not overlap. Besides, the majority of Polish natural scientists including a little less than half of all non-believers demonstrates aversion to the conflict narrative. My study reconstructs narrative strategies of the respondents that refer to the science-religion interconnection.
\end{abstract}

Keywords: science-religion relationship, in-depth interviews, natural scientists, narrative strategies

\section{Current State of Knowledge}

Most data on the subject is based on quantitative surveys of religious commitment among academics, which focus mainly on the United States and show that the level of religious belief is lower in the academy when compared to the general population. This data is interpreted, in general, within two paradigms: the paradigm of epistemological conflict between science and religion, and one that rejects this conflict. A pioneer of the conflict paradigm, the American psychologist James Leuba, suggested in the early $20^{\text {th }}$ century, that conflict between the two fields was the reason why elite scientists would more often reject religion. He found that $58 \%$ of American scientists disbelieved or expressed doubt in the existence of God, and that this rose to $70 \%$ among the "greatest" scientists. Leuba repeated this survey in 1934 and found that this tendency was even more significant $(67$ and $85 \%$, respectively) (Leuba 1916, 1934). As Leuba stressed, "in order to be again a vitalizing and controlling power in society, the religions will have to organize themselves around ultimate conceptions that are not in contradiction with the insights of the time" (1934, 300). In 1997-98 Larson and Witham replicated Leuba's research with similar results (Larson and Witham 1997, 1998).

Data from a 1958 poll of American graduate students was also analysed in secondary research by Rodney Stark. He found that those who attend elite institutions are the least likely to have a religious affiliation or regularly participate in worship services (these ideas he later rejected, Stark 2003). He wrote in 1963: "If this results in men of science having greater influence on our culture and value system (...) and if by becoming a scientist a man is likely to be detached from traditional religious orientations, then we must suspect that future American society will either become increasingly irreligious, or that religion will be extensively modified. In the latter case, the historical conflict between religion and science may be finally resolved" (Stark 1963, 14).

The second paradigm of sociological research into religious commitment among scientists challenges the idea of conflict. For example, Robert Wuthnow drew attention to the fact that natural scientists that embody the ideal of scientific method proved to be more religious than social scientists. He suggested the "boundary posturing mechanism" explanation -social scientists used it in order to create distance between themselves and the general public and in this way to be "more scientific" (Wuthnow 1985). Further, Edward Lehman and Donald Shriver spoke of a "scientific 
distance from religion" specific to social scientists where religion for them was an object of research. Elene Ecklund also emphasized, among other things, the religious socialization that remains the strongest predictor of religiosity among scientists (2010).

There are few surveys of the scientific community in Poland; all of them use quantitative methodology. The existing data confirms the lower religiosity of Polish scientists compared to the general population. The most extensive survey of Polish professors, carried out by M. LibiszowskaŻółkowska, provides valuable information in a variety of worldview areas of Polish scientists from various disciplines. The postal questionnaire $(N=447)$ received a score of $71.6 \%$ believing scientists compared to approximately $96-97 \%$ in the general population. "It seems that it is reasonable to say that professors are the group with the highest rate of atheism in Polish society," the sociologist says $(2000, \mathrm{~s} .83-84,95)$. This tendency is also evident in smaller samples: only $72.5 \%$ of the scientists employed at the Gdańsk University and $56.3 \%$ scientists surveyed by Andrzej Gołąb were believers (Erenc 2010, N = 281, Gołąb 2013, N = 186).

The only extensive qualitative analysis that focuses on the "cultural strategies" concerning science-religion relations employed by 275 scientists (in different disciplines) with regards to the science-religion relationship was carried out by the team of Elene Ecklund (Ecklund 2010). According to her data, scientists selectively employed different cultural strategies to explain the relationship of science and religion, such as: redefining categories (the use of institutional resources from religion and from science), integration models (scientists employed the views of major scientific actors to legitimate a symbiotic relationship between the two fields), and intentional talk (scientists engaged in discussions about the boundaries between science and religion). $15 \%$ of scientists said that religion and science were always in conflict, another $15 \%$ said they were never in conflict, and about $70 \%$ gave specific contexts in which religion and science are in conflict and others where they are not (Ecklund 2010).

There are no qualitative studies of the religious worldviews of scientists in Poland. Despite a broad discussion it is still unclear which factor is responsible for the lower religiosity of Polish scientists, and whether it lies within science itself or in the earlier biography of the scholar.

\section{Methodology and Characteristics of the Research Group}

The material for the analysis will be 50 in-depth interviews with biologists and physicists, employees of scientific research institutes of Polish Academy of Sciences and the largest universities in Poland, carried out in 2013-2014. The interviews were conducted at the Institute of Theoretical Physics, Institute of Biophysics and Biochemistry, Nicolaus Copernicus Astrophysics Center, in the departments of physics and biology of the Jagiellonian and Warsaw Universities. The purposive sample consisted of 25 physicists and 25 biologists, the search for which was carried out using the "snowball" method. They included 41 professors, 4 Doctors of Science without professorial titles, 2 $\mathrm{PhDs}$ and $3 \mathrm{MSc}$. $28 \%$ of the respondents were women, $72 \%$ of them were men.

The interviews were semi-structured in a very general way. We made every effort to allow respondents to spontaneously reveal their ideas and make it possible for them to share their reflections, arguments or discuss some difficult points. Only after the respondent spoke out in response to the first general questions do we entered into conversation using the topics of the interview guide. These can be joined into 4 sets: a). Science and religion. The starting question is: What, according to you, is the relationship between science and religion? Is there a conflict between the two? The next questions concerned understanding science and religion, the boundaries of both fields and their ability to provide answers about the universe and the human being, and among others, some ultimate questions. b). (Non)belief. This set includes questions concerning the "content" of faith (for believing respondents), the image of the supernatural, possible crises of faith and difficult points in belief; nonbelievers are asked about their reasons for rejection religion. We attempted to capture all possible contexts, which in this respect may refer to science. c). Image of the universe and human being.

The opening questions were: Do you think that the image of universe that is known to modern science makes a room for any form of the supernatural? Are there any scientific facts that make you think about the possibility of the supernatural or reject it? The answer created an opportunity to 
talk about ideas about the universe and the human being important for the respondent with regard to the topic of supernatural and some ultimate questions. When the respondents' spontaneous response was exhausted we asked questions formulated on the basis of the other collected interviews (in the Polish sample there were such topics as: the genesis of human being, the existence of the soul, life after death, conscience and mind, free will; the genesis of the universe, determinism in nature and human fate, human place in the infinite cosmos, the end of the world, the meaning of life and the universe). D). Biographical data. The last part of the conversation used an autobiographical narrative interview. The task of the respondent was to remember those episodes from their life story (childhood, school, college, adult life, scientific career, their own children) that were associated with her/his decisions concerning faith, attitude to institutional religion and choice of scientific career. The respondent tried to capture all moments in which they saw any interaction between science and religion.

\section{Worldview and Science-Religion Relationship}

It is advisable to briefly discuss the basic models of the relations between the science and religion in the human discourse. As discussed, they reduce themselves to the conflict and non-conflict paradigms. The conflict models are uniform: they assume that the epistemological conflict between the science and religion occurs since these areas respond to the same questions differently. We distinguish three models among the non-conflict ones: a) Non-Overlaping Magisterias Model (Gould 1998: the science is focused on the facts of the world structure, and the religion is focused on the values, meanings and purposes); b) complementary model legitimizing both the ways of reality description (they relate to the same reality, but speak of it in different, complementary, languages); c) synthesis model, which attempts to integrate the religious and scientific claims into a single system. Let these four models become the theoretical framework for the further theoretical analysis: we look for their elements in the empirical material. In view of the above-mentioned openness of the human worldview, we cannot talk about the integral models, therefore, we will use the term "strategy" to denote a method of the respondent reasoning, which refers to one of them.

On the base of the interviews it possible to characterize the faith of the respondents. $36 \%$ of respondents $(22 \%$ of physicists and $14 \%$ of biologists) were traditional Catholics, $14 \%$ ( $2 \%$ and $12 \%$ ) were Catholics but employed a broad interpretation of traditional Catholic doctrine, and $10 \%$ $(2 \%$ and $8 \%)$ believed in an impersonal supernatural power. Thus, the majority $(60 \%)$ of respondents believed in a supernatural reality, while the biologists were less likely to identify themselves with Catholicism in a traditional form. In contrast, $36 \%$ of respondents identified themselves as non-believers using term "atheist" $(20 \%$, or $12 \%$ of physicists and $8 \%$ of biologists) or "agnostic" (16\%, or $10 \%$ and $6 \%)$.

The first questions (What, according to you, is the relationship between science and religion? Is there a conflict between the two?) gave data that makes it possible to estimate the respondents' general orientations toward models of the science-religion relationship. The largest group (42\%) agreed with the idea that the areas of science and religion do not overlap, $24 \%$ said that science and religion are compatible but only if certain conditions are met, $8 \%$ spoke about their efforts to synthesize science and religion, and $4 \%$ were sure that synthesis is possible under specific conditions. This aversion to the conflict narrative demonstrated by the majority of Polish natural scientists $(78 \%$, including a little less than half of all non-believers) is significant and deserves attention. Only every fifth respondent (20\%) proved to be a supporter of the conflict model.

Below we will reconstruct the main strategies of the scientists concerning relations between the science and religion.

\section{Relations between the Science and Religion: Worldview Strategies}

\subsection{Non-Overlapping Magisterias Strategies}

The Non-Overlapping Magisterias thesis is often cited by the respondents, who want to emphasize the fact there is no conflict between the science and religion. However, different attributes were 
related to each of the areas. For example: - the science was seen as a sphere of rational inquiry, and the religion was considered an area of "something the science cannot rationally cognize" (physicist-believer); - the science was guided by the principle of empirical evidence, while for the faith "logical laws are nor affective" (physicist-believer); the religion told "that the world was created by God", and the science explained "how exactly it happened" (biologist-believer); the science was a verifiable knowledge, while the faith was the property of the brain (physicist-non-believer).

While the image of science was quite versatile and coincided with the criteria of the scientific method (it is empirical, rational, based on the intersubjective method and verifiable facts of the physical world), the concept of religion had different meanings (subjectively significant features were highlighted). The argumentation strategies postulated the following theses:

Limitation of human knowledge, based on which we can neither accept nor deny the existence of the supernatural. The monopoly of the scientific method in the field of the reality cognized was emphasized: "Even if Christ appeared before me, I would not be convinced; there is no naturalscience evidence for this" (physicist-believer).

Impossibility of the synthetic worldview as such due to the constant changeability of science: "... the attempts of such integration (...) is preparing of other catastrophes such as Darwin's. Even if we can put it together in a holistic concept, the science does not change" (biologist-believer).

No need for reflection on the theme of science and religion, at least in relation to their area, which the respondents perceived as an area of narrow knowledge that has no metaphysical implications: "I am far from the human biology, so, as a scientist, I am quite far from the matters of human nature and existence" (biologist-believer).

Rejection of religion as it is cognitively untenable is characteristic of both atheists and agnostics. Moreover, while atheists were sure that the supernatural does not exist, some agnostics conceded such possibility, but did not take it into account in view of its unprovedness: "I am an agnostic (...), but I am not sure there is no God, I just do not know it. In fact, you may not know it, as you may not know whether there is life on Mars" (physicist-non-believer).

\subsection{Complementary strategies}

The respondents, the responses of which had the elements of complementary models, declared there was no conflict between the science and religion, and also, as a rule, cited one of the versions of Gould's models. Complementarity appeared where there was a suspicion of intersection of two areas (for example, in matters of the origin of the world and men). The metaphorical language of the Scripture was emphasized, which complemented rather than competed with the scientific description: "Imagine me standing before the Jews four thousand years ago (...) and telling them how the Universe emerged. That there was a big bang, and then the quark-gluon matter appeared (...) it would be unclear, it would be some nonsense, so I cannot say such things at his level" (Professor of Physics, Catholic believer).

It is essential that a symbolic reading of the truths of faith opened a broad space for individual interpretation for many scientists, which sometimes was far beyond the traditional Catholicism: "Almighty God can perform miracles (...) I do not need any Divine Powers! (...) They are just stories!" (Physicist-believer).

\subsection{Synthesis strategies}

Synthesis strategy was used by the respondents-believers, who felt the need to create a consistent worldview: "For many years, I agreed with Gould's theory of two Magisterias (...), but I feel that we need to look for a more consistent worldview, and it's a little contradictory" (biologist-believer). The task, which a synthesis supporter set oneself, was so wide that the harmonization of the two areas was fragmentary, focusing on the subjectively difficult issues or points, where the harmony of science and religion was particularly obvious for the respondent. The synthetic strategies used the following arguments:

Limitation of human knowledge for the "Synthesis supporters" was a subjectively sufficient evidence of the potential possibility of the supernatural. Often, engagement in the science pushed 
for such a conclusion: "we see only what we need to survive. I look at this with a Darwinian view. So, even if fifteen different spirits were sitting here, if they do not affect us and we cannot contact them, we will not see them" (biologist-believer).

Realizing where the knowledge ends and faith begins, the scientists drew conclusions about the limitation of the synthesis itself: "The existence of the rules of physics (...) is a fact for me, which cannot be justified within the worldview (...) there is something superior (...) It's transcendence. What is transcendence? (...) I cannot understand more from the physics" (physicist-believer).

Possibility of "other religions" was mentioned by the scholars, who had their own ideas about the supernatural, and were sure that other religions would be more suitable for the science than the traditional Catholicism. However, they did not practice any of these religions.

Expansion of the scientific method, the revision of its naturalistic approach was mentioned very rarely. An example of it is the mathematical physicist-believer's reasoning of miracles, which were a confirmed evidence to him, but a fact not explained by the science: "I think that the question of supernatural phenomena is a key question (...) recognizing them as an element of the worldview, a part of this world of phenomena. And I think that hiding our heads in the sand because we cannot recreate them, because we cannot repeat them in the laboratory, is a bad solution."

\subsection{Conflict strategies}

For the conflict supporters, the objectivity of knowledge was of great importance, and they took the religious statements as evidence of the empirical world, which, consequently, related to the same reality as the scientific ones. The similar criteria of truth were applied to them. In this perspective, the religion was losing its credibility: "let's go back to the beginning, to a few amino acids. So, that Act of Creation means that God mixed the amino acids, which existed beyond the Earth, in a cup? This is primitive. It did not help me, and it is illogical" (biologist-non-believer); "Upon closer look, we can see the science and religion will be in conflict, because putting of questions, way of obtaining knowledge, search for answers in the science and religion are diametrically different" (biologist-nonbeliever).

\subsection{Delayed response}

The last small group of respondents included those who were not ready to give a definite answer to the question of the relations of science and religion. Their worldview was dynamic; they were torn between the belief and unbelief, confidence and uncertainty "it can be one way or another. Maybe I'm wrong. I always suggest several possible solutions, as well as the science does" (biologist that did not make a decision).

\section{Conclusions}

Although the interview analysis gave an idea of the huge variety of individual answers for the question of religion, we can draw some conclusions.

First of all, it should be noted that the majority (78\%) of the respondents denied the conflict between the science and religion. This shows the unwillingness of Polish scientists to participate in the ideological "wars", but it does not mean that the clash between the science and religion is not in their everyday experience. This confrontation can take place at one or multiple levels: logic level (attempt to reconcile the scientific data and the truths of religion), social level (reflections on the institutional relations between the two areas) and practical level (personal experience of their combination).

Further, the analysis of interviews helped to better understand the mechanisms of the demarcation between the science and religion in the Polish natural science community. The respondents have a clear understanding of the limits of scientific method and the competence of science. On the one hand, they have internalized the norms of scientific method, which is a legitimate source of knowledge about the world and men for Polish scientists. However, the respondents are responsible in relation to the boundaries of objective knowledge, knowing where 
the knowledge ends and the faith begins. At the same time, they tend to feel the limitation of scientific knowledge and human cognition. However, they make different conclusions out of this thesis. For some of them, the weakness of cognition indicates the potential possibility of the supernatural. Others tend to refuse the rationalization of faith and its acceptance through an act of will. The third group come to the conclusion about the impossibility of religion, which operates the unprovable assertions. The reasons for these differences can be partially explained by the biographical and social factors, but it seems that their idea of religion is important too.

While the scope of science is strictly defined, the religion is less regulated, inclusive; it allows a great interpretive maneuver. Even if the respondents feel that they are consistent Catholics, as a rule, they tend to accept the symbolic interpretation of the Scriptures, and sometimes of the Catholic dogmas too. In other cases, the traditional religion is rejected in favor of a vague "other religion", the search for which, however, is not conducted. Its purpose is obviously an extension of the individual interpretive field.

We can assume that the point of view of the conflict paradigm supporters is based on the refusal to consider the religion as a semantic field with "soft" boundaries, commitment to the scientific criteria of objective knowledge, which these respondents are inclined to apply to the religion truths, the question of supernatural being exclusively in the cognition area. This observation partially confirms the study conducted in 1998 by Polish sociologist Maria LibishovskayaZhultkovskaya among Polish professors (representatives of different sciences). For most respondents, the science and religion were not in conflict: $71.6 \%$ of the professors were believers and only $25.3 \%$ of them claimed their antireligious position. At the same time, $54 \%$ of respondentsnon-believers named the "scientific interpretation of reality" one of the reasons of their being nonbelievers. According to the sociologist, the main type of a professor-believer is a man for whom the crucial faith is the one that gives our life some meaning and supports in difficult times. For such a person the belief sometimes becomes a conscious choice, and sometimes is developed in the childhood. As for the non-religious type of a scholar, the disbelief for such people is an intelligent choice first. This group values the credibility of worldview above all, and questions the credibility of religion [6]. Our study has shown this conclusion is correct, with the only proviso that for the believing participants of our study the intellectual credibility of the worldview is as important as it is for the unbelieving ones. However, they did not apply the methodological requirements, developed in the framework of science, to the religion, allowing for the existence of other principles of cognition in the area of supernatural. In general, we can say that the more exclusive the scholar's understanding of the religion was, the harder it was for him to adhere to the paradigm of conflictfree relations between the science and religion.

\section{References}

Ecklund E. 2010. Science vs. Religion. What Scientists Really Think, Oxford: UP

Gołąb A. 2014. Poglądy wierzących i niewierzących naukowców na to, jakie cechy przypisuje Bogu większość Polaków, „Studia Sociologica”, nr VI (1), s. 144-162

Gould S. 1998. Non-overlapping magisteria. In Leonardo's mountain of clams and the diet of worms. New York: Harmony Books

Leuba J. 1916. The Belief in God and Immortality: A Psychological, Anthropological and Statistical Study. Boston: Sherman, French \& Co

Leuba J. 1934. Religious Beliefs of American Scientists. „Harper's Magazine” 169: 291-300

Libiszowska-Żółtkowska M., 2000, Wiara uczonych, Kraków: Nomos

Stark R. 2003. For the glory of God: How monotheism led to reformations, science, witch-hunts, and the end of slavery, Princeton

Stark R. 1963. On the Incompatibility of Religion and Science: A Survey of American Graduate Students. „Journal for the Scientific Study of Religion” 3/1: 3-20

Wuthnow R. 1985. Science and the sacred, w: The sacred in a secular age, ed. Ph. Hammond, Berkeley, CA: University of California Press, s. 187-203 